\title{
SIMULAÇÃO DO INTEMPERISMO NATURAL DE PILHAS ZINCO-CARBONO E ALCALINAS
}

\author{
Sílvio Carrielo Câmara e Júlio Carlos Afonso* \\ 149, B1. A, 21941-909 Rio de Janeiro - RJ, Brasil \\ Lilian Irene Dias da Silva, Nelma Nogueira Domingues e Arnaldo Alcover Neto \\ Centro de Tecnologia Mineral, Av. Pedro Calmon, 900, 21941-908 Rio de Janeiro - RJ, Brasil
}

Departamento de Química Analítica, Instituto de Química, Universidade Federal do Rio de Janeiro, Av. Athos da Silveira Ramos,

Recebido em 8/2/11; aceito em 14/6/11; publicado na web em 5/8/11

\begin{abstract}
SIMULATION OF NATUAL WEATHERING OF ZINC-CARBON AND ALKALINE BATTERIES. Spent alkaline and Zn-C batteries were placed in seawater, rainwater or landfill leachate at room temperature for up 30 days in order to simulate natural weathering. After the experiments $\mathrm{pH}$ and electrical conductivity of the liquid were measured. The precipitate formed and the filtrate were submitted to metal analysis by ICP-OES. Seawater is the most corrosive medium, followed by landfill leachate. $\mathrm{Pb}, \mathrm{Cd}$ and $\mathrm{Hg}$ were mainly in the filtrate. $\mathrm{Fe}, \mathrm{Mn}$ and $\mathrm{Zn}$ were generally dominant in the precipitate. $\mathrm{Na}$ and $\mathrm{K}$ account for the electrical conductivity and are good indicators of the corrosion stage of the batteries.
\end{abstract}

Keywords: spent batteries; weathering; heavy metals.

\section{INTRODUÇÃO}

Intemperismo é um conjunto de processos naturais de origem física (desagregação), química (decomposição) e biológica que causa a alteração dos materiais na superfície da Terra ao longo do tempo. ${ }^{1,2} \mathrm{O}$ produto desta deterioração é uma mistura de novos materiais que são estáveis no ambiente em que se deu a transformação. ${ }^{1}$ Esses processos são aplicáveis ao estudo de degradação e/ou decomposição de qualquer material disposto em condições naturais de superfície.

A lixiviação é o processo onde constituintes de um material sólido são liberados para o meio ambiente durante o contato com um fluxo de líquido por percolação ou difusão., ${ }^{3,4}$ A água, seja como reagente ou como solvente, é o principal agente do intemperismo. ${ }^{4} \mathrm{~A}$ solução contendo constituintes dissolvidos da fase sólida é chamada lixiviado. ${ }^{3}$ A capacidade de transferência dos constituintes da fase sólida para o lixiviado (lixiviabilidade) é determinada expondo-se o material a uma solução com características conhecidas e determinando-se o grau de dissolução dos contaminantes. ${ }^{4} \mathrm{~A}$ lixiviabilidade dos componentes depende de diversos fatores: tamanho de partícula (área superficial exposta); temperatura (solubilidade dos solutos na água); tempo de contato (estabelecimento ou não do equilíbrio de lixiviação); 3 agitação; relação líquido/sólido; $\mathrm{pH}$ (um dos fatores dominantes da mobilidade, solubilidade, complexação e retenção de metais pesados em solos, sedimentos e resíduos); ;,6 condições redox (importante quando os compostos formados na presença de oxigênio têm diferença significativa na solubilidade em relação àqueles formados sob condições redutoras); presença de agentes complexantes, $\mathrm{CO}_{2}$ e $\mathrm{O}_{2}$; presença de matéria orgânica dissolvida e em suspensão (ela influencia a biodisponibilidade e a mobilidade de metais pesados) $;{ }^{7,8}$ presença de micro-organismos (intemperismo biológico). ${ }^{1-3,9}$

A extensão da liberação de constituintes de um resíduo sólido em ensaios de lixiviação é fundamental para definir:9,10 o potencial de impacto ambiental através do transporte pela água, incluindo solo, lençol freático e contaminação de água de superfície; os riscos ecológicos e para a saúde humana a partir da disposição inadequada

\footnotetext{
*e-mail: julio@iq.ufrj.br
}

no ambiente; a eficácia de processos de tratamento de resíduos para disposição final; projetos e critérios de aceitação para instalação de programas de gerenciamento de resíduos; o controle de qualidade e classificação dos produtos e resíduos; o modo de degradação dos materiais dispostos no meio ambiente.

\section{Água da chuva}

Praticamente todos os materiais podem sofrer degradação pela ação da água da chuva, dependendo da sua acidez, composição e intensidade. ${ }^{11} \mathrm{O}$ clima úmido é o ambiente mais propício para a decomposição dos materiais, especialmente nas condições de umidade e calor existentes no Brasil, onde a velocidade das reações é acelerada pela temperatura e pela disponibilidade de $\mathrm{CO}_{2}$ e de ácidos orgânicos gerados pela vegetação. ${ }^{12,13}$

A composição química da água da chuva varia de região para região, devido às influências das emissões locais e das diferentes condições climáticas desses ambientes. ${ }^{12,13} \mathrm{O} \mathrm{pH}$ natural da água da chuva, considerando exclusivamente o equilíbrio com o $\mathrm{CO}_{2}$ atmosférico, é em torno de 5,6. ${ }^{10,14} \mathrm{~A}$ presença de poluentes, tais como óxidos de nitrogênio $\mathrm{NO}_{\mathrm{x}}\left(\mathrm{NO}_{2}, \mathrm{NO}\right)$ e de enxofre $\left(\mathrm{SO}_{2}, \mathrm{SO}_{3}\right)$ na presença de radiação solar, desencadeia reações gerando ácidos nítrico $\left(\mathrm{HNO}_{3}\right)$ e sulfúrico $\left(\mathrm{H}_{2} \mathrm{SO}_{4}\right)$, provocando uma redução do $\mathrm{pH}$ da água da chuva, constituindo a chamada chuva ácida. ${ }^{15,16}$ Os metais mais suscetíveis à corrosão induzida pela poluição, com especial destaque para o $\mathrm{SO}_{2}$, incluem $\mathrm{Fe}, \mathrm{Cu}, \mathrm{Zn}$ e ligas de $\mathrm{Al} .{ }^{17}$

\section{Água do mar}

A água do mar é composta por cerca de $96,5 \% \mathrm{~m} / \mathrm{m}$ de água, $2,5 \% \mathrm{~m} / \mathrm{m}$ de sais e quantidades menores de outras substâncias inorgânicas e orgânicas dissolvidas, material particulado e gases dissolvidos. ${ }^{18,19} \mathrm{O}$ pH da água do mar varia entre 7,4 e 8,4, devido principalmente ao efeito tampão do equilíbrio do sistema $\mathrm{H}_{2} \mathrm{CO}_{3} /$ $\mathrm{HCO}_{3}{ }^{-} / \mathrm{CO}_{3}{ }^{2-} \cdot{ }^{20,21}$ Outra propriedade importante é a elevada condutividade devido aos sais dissolvidos. A presença de grandes quantidades de sais dissolvidos na água do mar confere a ela a classificação de eletrólito forte, tornando-a um agente intempérico natural extremamente agressivo aos materiais expostos à atmosfera 
marinha ou em contato direto com ela. ${ }^{20}$ Além disso, a presença de grandes quantidades de compostos orgânicos, gases dissolvidos (especialmente $\mathrm{O}_{2}$ e $\mathrm{CO}_{2}$ ) e a existência de vidas biológicas distintas, contribui para o aumento de sua ação corrosiva e da intensificação do intemperismo. ${ }^{20}$

\section{Chorume}

O chorume é o efluente líquido gerado como consequência da percolação da água da chuva através de camadas de resíduos depositados em um aterro. ${ }^{22-24}$ Possui coloração escura e elevadas cargas orgânica e inorgânica, produzidas pela decomposição física, química e biológica dos resíduos. É uma matriz extremamente complexa e sua composição depende da idade do aterro..$^{22,23,25}$

\section{Interação de pilhas e baterias com o meio ambiente}

Nas últimas décadas, houve um extraordinário desenvolvimento tecnológico no setor da indústria eletroeletrônica, o que vem provocando preocupações ambientais devido à geração de grandes quantidades de resíduos eletroeletrônicos, incluindo pilhas e baterias.

No Brasil, a maioria das pilhas e baterias depois de utilizada ainda é descartada junto com o lixo domiciliar. ${ }^{3,26}$ A grande maioria dos municípios brasileiros não possui formas adequadas de tratamento e disposição final de resíduos, os quais podem ser depositados a céu aberto (lixões), ou em aterros controlados. Essas formas inadequadas de disposição podem provocar vazamento dos metais pesados presentes em pilhas e baterias. ${ }^{3}$ Além disso, a queima em incineradores também gera problemas ambientais, pois os resíduos tóxicos permanecem nas cinzas e parte deles pode volatilizar, contaminando a atmosfera. ${ }^{27}$

Segundo a norma brasileira NBR 10.004 da Associação Brasileira de Normas Técnicas (ABNT) ${ }^{28}$ pilhas e baterias apresentam características de toxicidade (devida a metais pesados), corrosividade e reatividade (devidas ao eletrólito), classificando-as como resíduos perigosos (classe I). Esses produtos precisam receber uma destinação final diferente de aterros sanitários, aterros controlados e muito menos lixões.

Nos EUA, os produtores de pilhas e baterias e administradores de aterros licenciados são obrigados a realizar testes de percolação ou lixiviação para pilhas e baterias. ${ }^{29} \mathrm{O}$ teste adotado é o TCLP (Toxicity Characteristic Leaching Procedure), ${ }^{30}$ baseado em quatro critérios de periculosidade: inflamabilidade, corrosividade, reatividade e toxicidade, este último determinado pelas características de lixiviação ou percolação do sistema ambiental. Um resíduo é considerado perigoso se apresentar pelo menos uma dessas características. $^{30,31}$

Pilhas e baterias, mesmo dentro dos padrões de $\mathrm{Pb}, \mathrm{Cd}$ e $\mathrm{Hg}$ estabelecidos pela Resolução 401/2008 do Conselho Nacional de Meio Ambiente (CONAMA), ${ }^{32}$ podem conter quantidades apreciáveis de $\mathrm{Zn}$ e $\mathrm{Mn}$, metais pesados que não são contemplados pela legislação vigente.

As pilhas possuem aspectos favoráveis aos processos corrosivos, uma vez que representam uma célula de corrosão. Outro fato é que possuem junções de suas conexões (principalmente nos polos positivo e negativo e no invólucro externo), que podem proporcionar áreas críticas para desencadear processos corrosivos e, assim, provocar vazamentos, expondo a pasta eletrolítica, o catodo, o anodo e outros componentes ao meio ambiente.

Estudos recentes demonstram que a chuva ácida pode contribuir para a contaminação do solo por metais pesados, provenientes de pilhas e baterias. Em um desses estudos, ${ }^{33}$ ao se avaliar o comportamento de pilhas alcalinas em colunas de solos frente à solução de
$\mathrm{HNO}_{3}+\mathrm{H}_{2} \mathrm{SO}_{4} 1: 1(\mathrm{pH}=4)$ durante 1 ano, verificou-se um aumento das concentrações de $\mathrm{Zn}$ e Mn e uma diminuição do $\mathrm{pH}$ do solo. Em outro trabalho, ${ }^{34}$ após lixiviação de colunas de latossolo contendo pilhas $\mathrm{Zn}-\mathrm{C}$ com solução de $\mathrm{HNO}_{3}+\mathrm{H}_{2} \mathrm{SO}_{4}(\mathrm{pH}=4)$, observou-se um aumento das concentrações desses metais tanto no lixiviado como no solo, na seguinte ordem: $\mathrm{Zn}>\mathrm{Mn}>\mathrm{Pb}>\mathrm{Cr}>\mathrm{Cu}>\mathrm{Ni}>\mathrm{Cd}$.

Um controle ambiental apropriado somente é possível com uma coleta seletiva de pilhas e baterias usadas, seguida de inertização (para disposição em aterros industriais para materiais classe I) ou valorização como insumo em processos de reciclagem. ${ }^{26,35} \mathrm{~A}$ Lei 12.305 (Política Nacional de Resíduos Sólidos), ${ }^{36}$ sancionada pelo Presidente da República em agosto de 2010, disciplina o manejo correto de produtos usados com alto potencial de impacto ambiental. $\mathrm{O}$ inciso II do artigo $33^{\circ}$ da Lei 12.305 indica que pilhas e baterias devem possuir um sistema de logística reversa a partir do retorno do produto usado pelo consumidor, envolvendo fabricantes, importadores, distribuidores e comerciantes. Reforçando o disposto na Resolução 401/2008 do CONAMA, ${ }^{32}$ pilhas e baterias usadas não podem ser descartadas em corpos hídricos e lançadas ou queimadas a céu aberto, afora outras formas vedadas pelo poder público (como terrenos baldios e lixões).

O objetivo deste trabalho foi realizar testes de lixiviação de pilhas alcalinas e Zn-C em água da chuva, água do mar e chorume, simulando ambientes de intemperismo natural, verificando os parâmetros físico-químicos que aceleram esse processo, e verificar o potencial de risco de contaminação ambiental decorrente desses produtos. Os meios de lixiviação escolhidos representam grandemente a situação de degradação que as pilhas (e baterias) descartadas de forma inadequada poderão sofrer no meio ambiente.

\section{PARTE EXPERIMENTAL}

\section{Pilhas utilizadas}

Pilhas alcalinas (um fabricante) e $\mathrm{Zn}-\mathrm{C}$ (dois fabricantes) novas, de tamanho AA (a mais consumida no mercado), foram adquiridas no comércio varejista. Todas as pilhas de uma mesma marca (por tipo) pertenciam a um mesmo lote, visando minimizar as variações de composição inerentes aos processos de fabricação. As pilhas foram descarregadas utilizando equipamentos elétricos (MP3, discman e lanterna). Em seguida, foram pesadas em balança analítica e guardadas separadamente, de acordo com a marca, em frascos plásticos para os ensaios.

\section{Agentes lixiviantes}

\section{Água da chuva}

A água da chuva foi coletada em março de 2008 na cidade do Rio de Janeiro, bairro de Santa Cruz, a $20 \mathrm{~km}$ da área industrial do referido bairro (aproximadamente $60 \mathrm{~km}$ do centro da cidade e $30 \mathrm{~km}$ das praias do Recreio e Barra da Tijuca). Foram utilizados quatro potes plásticos novos de $5,0 \mathrm{~L}$ suspensos em piquetes a aproximadamente $1 \mathrm{~m}$ da superfície do solo, para evitar a possível mistura da água da chuva com este. Desprezaram-se as primeiras amostras de água após 15 min para evitar concentrações mais elevadas dos constituintes característicos das primeiras águas de chuvas. As amostras foram mantidas sob refrigeração para posterior análise físico-química.

\section{Água do mar}

A água do mar foi coletada na praia de Grumari, zona oeste da cidade do Rio de Janeiro. É considerada uma praia não poluída, uma vez que é isolada por montanhas e não tem moradias e atividades 
industriais ao longo de sua orla. Foi feita uma amostragem direta para recipiente de plástico de PVC de $20 \mathrm{~L}$, a cerca de $15 \mathrm{~m}$ da areia. A amostra foi mantida sob refrigeração para posterior análise físico-química.

\section{Chorume}

A amostra de chorume foi coletada de uma lagoa de um aterro sanitário licenciado do Estado do Rio de Janeiro. A amostragem foi feita imergindo um frasco de PVC de $20 \mathrm{~L}$ aproximadamente no cento da lagoa. A análise físico-química da amostra foi feita pela própria empresa.

A condutividade dos três meios lixiviantes foi medida com um condutivímetro digital com célula de condutividade de platina, previamente calibrado com soluções padrão de $\mathrm{KCl}$. A temperatura e a umidade relativa do ambiente foram registradas para calibração do instrumento. $\mathrm{O} \mathrm{pH}$ foi determinado por meio de um peagâmetro digital.

\section{Ensaios de lixiviação}

Foi utilizado ensaio de lixiviação estático, que consistiu na imersão total das pilhas no líquido de ensaio. Foram utilizados frascos de vidro novos $(250 \mathrm{~mL})$, providos com tampa rosqueada plástica. Alíquotas de $150 \mathrm{~mL}$ do lixiviante, medidos em proveta graduada, foram transferidas para os frascos; em seguida, imergiu-se a pilha (os ensaios foram feitos em duplicata para cada teste). A tampa foi fechada e foram programadas retiradas após 1, 7 e 30 dias.

Após o ensaio determinaram-se o $\mathrm{pH}$ e a condutividade do lixiviado. Após as medidas, filtrou-se a solução em papel de filtro de filtração rápida, sendo o filtrado coletado em frasco plástico e conservado sob refrigeração para a análise química.

O precipitado obtido na filtração foi seco à temperatura ambiente, pesado em balança analítica e digerido com $\mathrm{HCl}$ concentrado para massas pequenas $(<1 \mathrm{~g})$, ou água régia recém-preparada (para massas superiores a $1 \mathrm{~g}$ ). Essa digestão foi realizada sob aquecimento brando $\left(40^{\circ} \mathrm{C}\right)$ e agitação manual por $30 \mathrm{~min}(1 \mathrm{~mL}$ solução ácida 100 $\mathrm{mg}^{-1}$ sólido). $\mathrm{O}$ extrato foi transferido quantitativamente para frasco plástico novo e mantido sob refrigeração para a análise química.

\section{Análise química}

Uma alíquota de $25 \mathrm{~mL}$ de cada um dos filtrados ou de cada agente lixiviante e $30 \mathrm{~mL}$ de água régia recém-preparada foram adicionados a um tubo digestor com dedo frio, em uma capela. No caso das soluções ácidas, após a digestão dos precipitados, a razão alíquota/água régia foi $1: 2 \mathrm{v} / \mathrm{v}$. A mistura foi aquecida durante $1 \mathrm{~h} \mathrm{a}$ $80{ }^{\circ} \mathrm{C}$. Os extratos digeridos foram filtrados em papel de filtro para um balão volumétrico (25-100 mL), avolumados com água Milli-Q, e mantidos sob refrigeração para a análise química.

$\mathrm{Fe}, \mathrm{Mn}, \mathrm{Zn}$ (elementos principais constituintes das pilhas ${ }^{37}$ ) e $\mathrm{Pb}$, Cd, Hg (elementos citados na Resolução 401/2008 do CONAMA ${ }^{32}$ ) foram determinados por ICP-OES. Na e K (presentes nos eletrólitos das pilhas ${ }^{3}$ ) foram analisados por espectrometria de absorção atômica. As análises foram feitas em duplicata com dois brancos para controle (meio lixiviante e água régia + água Milli-Q ou $\mathrm{HCl}$ concentrado + água Milli-Q), conforme a origem da amostra em análise. Foram preparadas soluções padrão mistas dos metais a serem analisados em $\mathrm{HNO}_{3} 3 \%$ v/v, a partir de soluções padrão individuais para a construção das curvas de calibração na faixa $0,5-500 \mu \mathrm{g} \mathrm{L}^{-1}(\mathrm{Mn}, \mathrm{Zn}$, $\mathrm{Fe}, \mathrm{Hg}, \mathrm{Cd}, \mathrm{Pb}$ ) e 0,1-50 mg L-1 (Na, K).

Amostras das pilhas descarregadas foram analisadas segundo procedimento descrito na literatura ${ }^{37}$ para determinação da quantidade média $(\% \mathrm{~m} / \mathrm{m})$ dos metais pesados supracitados nas pilhas inteiras.

\section{RESULTADOS E DISCUSSÃO}

\section{Condutividade e pH dos lixiviados}

$\mathrm{O}$ valor final de $\mathrm{pH}$, levemente ácido (6,5, Tabela 1), obtido nos ensaios com água da chuva foi o mesmo para todas as pilhas. Esse resultado está de acordo com a literatura, ${ }^{38}$ a qual relata que a lixiviação (em curtos períodos) de pilhas alcalinas e $\mathrm{Zn}-\mathrm{C}$ e baterias Ni-Cd e Ni-MH em aterros simulados produziu um lixiviado com $\mathrm{pH}$ médio de 5,85 . Esse fato sugere que a água da chuva, durante o período dos ensaios, não foi agressiva a ponto de provocar vazamento significativo de componentes internos. Caso isso acontecesse, por exemplo, o pH

Tabela 1. Valores médios de pH e condutividade $\left(25^{\circ} \mathrm{C}\right)$ dos lixiviados após ensaios estáticos de lixiviação de pilhas por imersão

\begin{tabular}{|c|c|c|c|c|c|c|}
\hline \multirow[t]{2}{*}{ Pilha } & \multirow[t]{2}{*}{ Lixiviante } & \multirow[t]{2}{*}{ Parâmetro } & \multicolumn{4}{|c|}{ Tempo (dias) } \\
\hline & & & $0 *$ & 1 & 7 & 30 \\
\hline \multirow{6}{*}{ Alcalina } & \multirow[t]{2}{*}{ Água da chuva } & $\mathrm{pH}$ & 5,5 & 6,5 & 6,5 & 6,5 \\
\hline & & Cond. $\left(\mu \mathrm{S} \mathrm{cm}^{-1}\right)$ & $2,4 \pm 0,1$ & $6,1 \pm 0,7$ & $8,4 \pm 1,6$ & $12,8 \pm 0,3$ \\
\hline & \multirow[t]{2}{*}{ Água do mar } & $\mathrm{pH}$ & 7,5 & 7,5 & 8,5 & 11,0 \\
\hline & & Cond. $\left(\mathrm{mS} \mathrm{cm}^{-1}\right)$ & $74,5 \pm 0,4$ & $51,6 \pm 0,8$ & $53,9 \pm 0,1$ & $64,2 \pm 1,5$ \\
\hline & \multirow[t]{2}{*}{ Chorume } & $\mathrm{pH}$ & 7,6 & 8,5 & 8,5 & 10,0 \\
\hline & & Cond. $\left(\mathrm{mS} \mathrm{cm}^{-1}\right)$ & $16,7 \pm 0,2$ & $16,1 \pm 0,1$ & $15,4 \pm 0,2$ & $16,8 \pm 0,2$ \\
\hline \multirow{6}{*}{$\mathrm{Zn}-\mathrm{C}$} & \multirow[t]{2}{*}{ Água da chuva } & $\mathrm{pH}$ & 5,5 & 6,5 & 6,5 & 6,5 \\
\hline & & Cond. $\left(\mu \mathrm{S} \mathrm{cm}^{-1}\right)$ & $2,4 \pm 0,1$ & $2,9 \pm 0,4$ & $20,8 \pm 1,8$ & $25,9 \pm 5,3$ \\
\hline & \multirow[t]{2}{*}{ Água do mar } & $\mathrm{pH}$ & 7,5 & 6,5 & 5,8 & 6,0 \\
\hline & & Cond. $\left(\mathrm{mS} \mathrm{cm}^{-1}\right)$ & $74,5 \pm 0,4$ & $51,1 \pm 0,1$ & $50,9 \pm 0,2$ & $60,8 \pm 1,1$ \\
\hline & \multirow[t]{2}{*}{ Chorume } & $\mathrm{pH}$ & 7,6 & 8,5 & 8,5 & 9,0 \\
\hline & & Cond. $\left(\mathrm{mS} \mathrm{cm}^{-1}\right)$ & $16,7 \pm 0,2$ & $16,4 \pm 0,6$ & $14,7 \pm 0,5$ & $15,6 \pm 0,1$ \\
\hline \multirow{6}{*}{ Zn-C II } & \multirow[t]{2}{*}{ Água da chuva } & $\mathrm{pH}$ & 5,5 & 6,5 & 6,5 & 6,5 \\
\hline & & Cond. $\left(\mu \mathrm{S} \mathrm{cm}^{-1}\right)$ & $2,4 \pm 0,1$ & $4,9 \pm 0,2$ & $13,0 \pm 1,8$ & $15,5 \pm 1,9$ \\
\hline & \multirow[t]{2}{*}{ Água do mar } & $\mathrm{pH}$ & 7,5 & 5,5 & 5,0 & 5,0 \\
\hline & & Cond. $\left(\mathrm{mS} \mathrm{cm}^{-1}\right)$ & $74,5 \pm 0,4$ & $51,1 \pm 0,9$ & $50,5 \pm 0,7$ & $59,1 \pm 0,1$ \\
\hline & \multirow[t]{2}{*}{ Chorume } & $\mathrm{pH}$ & 7,6 & 8,5 & 8,5 & 9,0 \\
\hline & & Cond. $\left(\mathrm{mS} \mathrm{cm}^{-1}\right)$ & $16,7 \pm 0,2$ & $16,4 \pm 0,2$ & $15,0 \pm 0,4$ & $15,3 \pm 0,9$ \\
\hline
\end{tabular}

* 0 dias: lixiviante in natura 
do lixiviado da pilha alcalina seria básico devido à base forte $(\mathrm{KOH})$ presente em sua pasta eletrolítica.

Nos ensaios com água do mar os dados da Tabela 1 indicam que o $\mathrm{pH}$ dos lixiviados apresentou maior variabilidade. Nos ensaios com as pilhas alcalinas, o pH atingiu 8,5 e 11,0 após 7 e 30 dias, respectivamente. Isso indica que houve vazamento da pasta eletrolítica. No caso das pilhas $\mathrm{Zn}-\mathrm{C}$ houve uma diminuição gradativa do $\mathrm{pH}$, estabilizando-se na faixa 5-6 ao final de 30 dias (Tabela 1). Isso também indica vazamento da pasta eletrolítica. A presença de $\mathrm{NH}_{4} \mathrm{Cl}$, que faz parte do eletrólito dessas pilhas, foi confirmada no lixiviado por testes qualitativos para $\mathrm{NH}_{4}{ }^{+} .{ }^{39}$

Nos ensaios com chorume, todos os lixiviados apresentaram o mesmo comportamento - um aumento gradual do valor de $\mathrm{pH}$ - de 7,6 para 9 (pilhas $\mathrm{Zn}-\mathrm{C}$ ) ou 10 (pilhas alcalinas) ao final de 30 dias. Se para a pilha alcalina esse fato é perfeitamente compatível com o $\mathrm{pH}$ de seu eletrólito, o comportamento visto para as pilhas $\mathrm{Zn}-\mathrm{C}$, cujo eletrólito possui $\mathrm{pH}$ ácido, pode ser explicado pelo efeito de tamponamento da matéria orgânica do chorume (ácidos húmicos, fúlvico, etc)..$^{22,25}$

A condutividade dos lixiviados apresentou elevação com o tempo para a água de chuva (Tabela 1). Para as pilhas $\mathrm{Zn}-\mathrm{C}$ verificaram-se elevações consideráveis na condutividade ao se passar de 1 para 7 dias de ensaio, e uma elevação mais branda ao se passar de 7 para 30 dias. Esse fato indica que, mesmo sem indicação visual, houve certa liberação de componentes internos das pilhas, alterando ligeiramente o $\mathrm{pH}$ original da água da chuva $(5,5) \mathrm{e}$, principalmente, a condutividade. Os lixiviados das pilhas alcalinas tiveram um aumento menos acentuado da condutividade. Essa pilha possui uma blindagem externa mais espessa, devido à natureza corrosiva de sua pasta eletrolítica quando comparada às pilhas $\mathrm{Zn}-\mathrm{C} .{ }^{3,37}$ Isto sugere uma menor lixiviabilidade dessas pilhas na presença de um meio pouco agressivo como a água da chuva.

Nos ensaios com água do mar, os lixiviados de todas as pilhas apresentaram comportamento bastante semelhante (Tabela 1): diminuição do valor de condutividade após um dia, atingindo praticamente o mesmo valor (aproximadamente $51,0 \mathrm{mS} \mathrm{cm}^{-1}$ ), seguido de elevação, principalmente para as pilhas alcalinas, nos períodos subsequentes. A diminuição significativa no valor de condutividade após um dia de imersão pode ser atribuída à formação de precipitados decorrentes da corrosão das pilhas. Sabe-se que os meta-hidróxidos FeOOH e $\mathrm{MnOOH}$ possuem elevada capacidade de adsorção e retenção de metais em solos e águas naturais, como a água do mar. ${ }^{40-42} \mathrm{~A}$ literatura assinala ainda que produtos de corrosão de ferro e zinco em ambientes marinhos, como $\mathrm{Fe}(\mathrm{OH})_{3}, \mathrm{FeOOH}, \mathrm{Zn}_{5}\left(\mathrm{CO}_{3}\right)_{2}(\mathrm{OH})_{6}, \mathrm{Zn}_{5}(\mathrm{OH})_{8} \mathrm{Cl}_{2}$. $\mathrm{H}_{2} \mathrm{O}$ e $\mathrm{NaZn}_{4} \mathrm{Cl}(\mathrm{OH})_{6} \mathrm{SO}_{4} \cdot 6 \mathrm{H}_{2} \mathrm{O}$, são um indicativo de diminuição das concentrações de sais dissolvidos devido a processos de retenção, tais como sorção e precipitação. ${ }^{40-44}$ De acordo com a literatura, a maioria dos metais pesados possui um mínimo de solubilidade em $\mathrm{pH}$ alcalino (8-11) e apresenta um aumento de solubilidade considerável em valores normalmente abaixo de 5 e acima de $11 .^{11,45} \mathrm{O}$ aumento de condutividade verificado nos períodos de 7 e 30 dias deve estar associado à presença de eletrólitos $\left(\mathrm{NH}_{4} \mathrm{Cl}\right.$ ou $\left.\mathrm{KOH}\right)$ liberados das pastas eletrolíticas, como também sugerido pela variação do $\mathrm{pH}$ desses lixiviados.

Nos ensaios com chorume, a condutividade apresentou pouca variação. Um mínimo foi observado ao final de 7 dias, seguido de pequena elevação após 30 dias, lembrando o comportamento da água do mar. Um fato a considerar é a presença de matéria orgânica nessa matriz. De acordo com a literatura, ela possui elevada afinidade por metais, e estes podem ser retidos via complexação por essas substâncias..$^{25,40,46}$ Processos de precipitação e sorção pelo material particulado presente no chorume podem também justificar os resultados de $\mathrm{pH}$ e condutividade observados na Tabela $1 .^{25,47,48}$

\section{Precipitados obtidos após os ensaios de lixiviação}

A Tabela 2 apresenta as massas obtidas dos precipitados em função dos tempos de lixiviação. Após 1 dia, não houve formação de precipitado nos ensaios com água da chuva, enquanto que houve formação de pequena quantidade no caso da água do mar e do chorume (em torno de 0,3 e 1,4 g, respectivamente, para todas as pilhas). A maior massa no caso do chorume deve ser atribuída à presença de material particulado e matéria orgânica pré-existentes, característica desse meio (a amostra de chorume original possui 9,3 $\pm 0,1 \mathrm{~g} \mathrm{~L}^{-1} \mathrm{de}$ sólidos totais em suspensão). ${ }^{22,25,48}$

Tabela 2. Massas (em g) dos precipitados obtidos após ensaios estáticos de lixiviação das pilhas por imersão

\begin{tabular}{llccc}
\hline Pilha & Lixiviante & \multicolumn{3}{c}{ Tempo (dias) } \\
\cline { 3 - 5 } & & 1 & 7 & 30 \\
\hline \multirow{3}{*}{ Alcalina } & Água da chuva & 0 & 0,1 & 3,0 \\
& Água do mar & 0,3 & 5,2 & 2,0 \\
& Chorume & 1,4 & 1,6 & 3,0 \\
\hline \multirow{2}{*}{ Zn-C I } & Água da chuva & 0 & 0,1 & 1,6 \\
& Água do mar & 0,2 & 0,9 & 0,3 \\
& Chorume & 1,3 & 2,1 & 2,7 \\
\hline \multirow{3}{*}{ Zn-C II } & Água da chuva & 0 & 0,1 & 1,3 \\
& Água do mar & 0,3 & 1,0 & 0,4 \\
& Chorume & 1,4 & 1,8 & 2,8 \\
\hline
\end{tabular}

As massas dos precipitados aumentaram progressivamente com o aumento do tempo de lixiviação para a água da chuva e o chorume, especialmente de 7 para 30 dias. A faixa de $\mathrm{pH}$ desses lixiviados favorece a precipitação de metais pesados liberados de pilhas. ${ }^{11,45,49,50}$ Isso sugere liberação de componentes internos das mesmas após um tempo de ensaio suficientemente longo. As massas maiores verificadas com o chorume podem ser, em parte, devidas à pré-existência de matéria orgânica e material particulado nessa matriz.

A água do mar apresentou um comportamento diferente. Houve um aumento muito significativo da massa de precipitado de 1 para 7 dias, com destaque para a pilha alcalina. O efeito visual da água do mar sobre as pilhas é notável. Em todas elas, já ao final de 1 dia, observou-se uma massa marrom-alaranjada, contendo ferro e manganês. ${ }^{39}$ A partir de 7 dias, observou-se uma tonalidade opalescente/ translúcida do filtrado, de cor alaranjada, característica de compostos de ferro em estado coloidal. A diminuição da massa ao final de 30 dias deve ser atribuída a esse fenômeno (material sólido não filtrável). Uma massa gelatinosa de cor branca também apareceu após 7 dias de imersão, suspeitando ser devida a compostos de zinco.

No caso da água da chuva, somente após 30 dias houve um início de corrosão nos polos das pilhas. O chorume mostrou indicativo visual de corrosão após 7 dias. Assim, nos critérios visual e de formação de preciptiados, a água da chuva se mostrou o meio menos agressivo. Essa matriz, quando comparada às outras duas, é a menos complexa química e biologicamente.

\section{Liberação de metais das pilhas}

\section{$\mathrm{Pb}, \mathrm{Cd}$ e $\mathrm{Hg}$}

As Figuras 1 e 2 apresentam a quantidade $(\% \mathrm{~m} / \mathrm{m}) \mathrm{de} \mathrm{Pb}, \mathrm{Cd}$ e Hg liberada das pilhas imersas em água da chuva e água do mar. No caso do chorume, as quantidades liberadas desses elementos, tanto no lixiviado como no precipitado, ficaram abaixo do limite de detecção do método analítico. As quantidades liberadas são muito 
pequenas (inferiores a 3,5\% m/m do total). Os metais sob discussão predominam largamente $(>90 \%)$ nos lixiviados, independentemente do tipo de pilha e do $\mathrm{pH}$ (Tabela 1). Apesar disso, as concentrações em todos os lixiviados são extremamente baixas $\left(\mathrm{Pb}<10 \mu \mathrm{g} \mathrm{L}^{-1}\right.$; $\mathrm{Cd}<2 \mu \mathrm{g} \mathrm{L}^{-1} ; \mathrm{Hg}<1 \mu \mathrm{g} \mathrm{L}^{-1}$ ), sendo inclusive inferiores aos limites prescritos pela norma NBR 10004 (Anexo G) ${ }^{28}$ para os ensaios de solubilização segundo a norma NBR $10005\left(\mathrm{~Pb}-10 \mu \mathrm{g} \mathrm{L}{ }^{-1} ; \mathrm{Cd}-5\right.$ $\left.\mu \mathrm{g} \mathrm{L}{ }^{-1} ; \mathrm{Hg}-1 \mu \mathrm{g} \mathrm{L}^{-1}\right){ }^{28}$ Embora o $\mathrm{pH}$ dos lixiviados seja favorável (Tabela 1) à precipitação desses elementos, a baixa concentração dos mesmos se sobrepõe ao fator $\mathrm{pH}$. $\mathrm{O}$ fato de o mercúrio ser o elemento em menor concentração está de acordo com o baixo teor encontrado para esse elemento nas pilhas do presente estudo (Tabela 3) ${ }^{37}$ Outros estudos recentes indicam que as concentrações de $\mathrm{Pb}, \mathrm{Cd}$ e $\mathrm{Hg}$ em pilhas alcalinas e $\mathrm{Zn}$-C estão dentro ou mesmo muito abaixo dos limites estabelecidos pelas resoluções atuais de diversos países. ${ }^{51,52}$

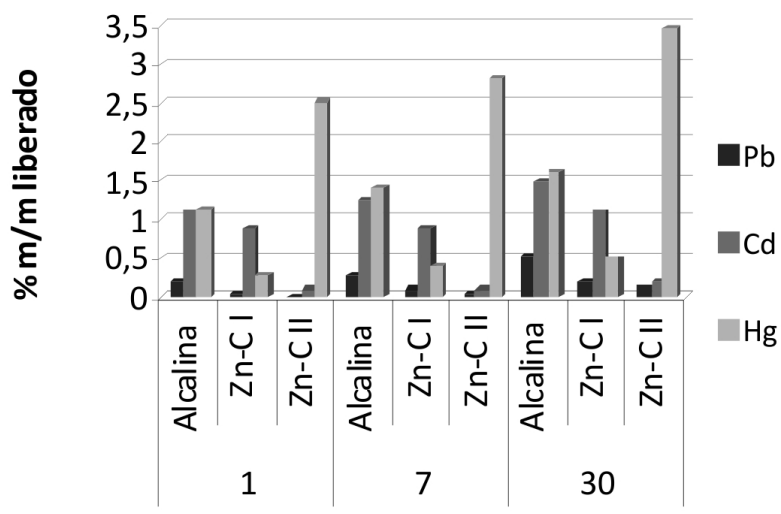

\section{dias}

Figura 1. Percentual $(\mathrm{m} / \mathrm{m})$ de $\mathrm{Pb}, \mathrm{Cd}$ e $\mathrm{Hg}$ liberados das pilhas em relação à quantidade total presente nas mesmas nos ensaios com água da chuva

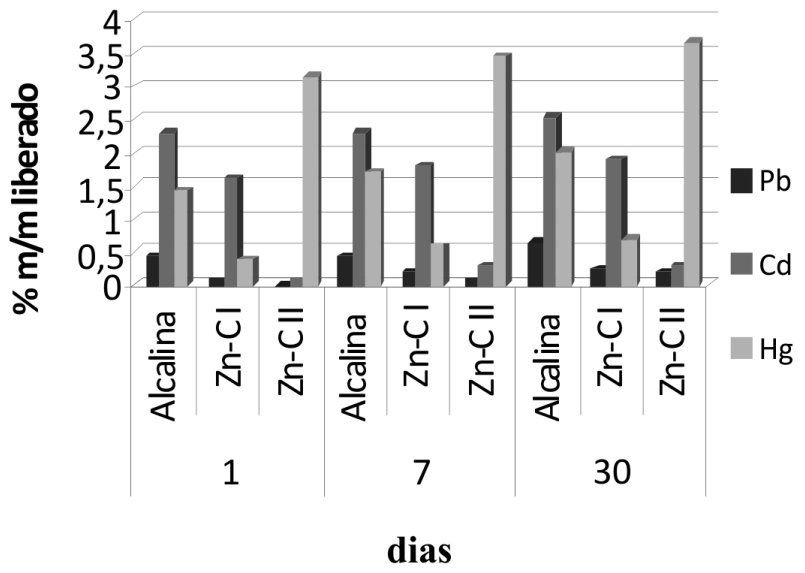

Figura 2. Percentual $(\mathrm{m} / \mathrm{m})$ de $\mathrm{Pb}, \mathrm{Cd}$ e Hg liberados das pilhas em relação à quantidade total presente nas mesmas nos ensaios com água do mar

Tabela 3. Quantidade total média $\left(\mathrm{mg} \mathrm{kg}^{-1}\right)$ de metais presentes nas pilhas

\begin{tabular}{cccc}
\hline Metal & Pilha alcalina & Pilha Zn-C I & Pilha Zn-C II \\
\hline $\mathrm{Pb}$ & $1,8 \times 10^{1}$ & $9,0 \times 10^{1}$ & $6,1 \times 10^{2}$ \\
$\mathrm{Cd}$ & $3,5 \times 10^{-1}$ & $4,8 \times 10^{-1}$ & $3,8 \times 10^{1}$ \\
$\mathrm{Hg}$ & $7,0 \times 10^{-2}$ & $3,0 \times 10^{-2}$ & $2,5 \times 10^{1}$ \\
$\mathrm{Fe}$ & $2,4 \times 10^{2}$ & $1,2 \times 10^{3}$ & $3,1 \times 10^{4}$ \\
$\mathrm{Mn}$ & $4,4 \times 10^{5}$ & $1,3 \times 10^{5}$ & $1,6 \times 10^{5}$ \\
$\mathrm{Zn}$ & $2,1 \times 10^{5}$ & $1,5 \times 10^{5}$ & $9,6 \times 10^{4}$ \\
\hline
\end{tabular}

Na água do mar (Figura 2) observa-se um aumento da quantidade de $\mathrm{Pb}, \mathrm{Cd}$ e $\mathrm{Hg}$ removidos das pilhas em relação à água da chuva (Figura 1). O tempo de imersão teve relativamente pouca influência para cada pilha considerada em ambos os meios.

\section{$\mathrm{Fe}, \mathrm{Mn}$ e $\mathrm{Zn}$}

As Figuras 3 e 4 indicam as quantidades de Fe liberadas das pilhas após os ensaios de imersão total em água da chuva/chorume e em água do mar, respectivamente, enquanto que os dados para $\mathrm{Zn}$ e Mn se encontram nas Figuras 5 a 7. A Tabela 4 mostra os percentuais de cada um desses metais liberados presentes nos precipitados que se formaram ao longo dos experimentos.

É notável a quantidade de ferro liberada nos ensaios com a água do mar (Figura 4), muito maior do que nos outros meios (Figura 3), particularmente na pilha alcalina. Deve-se esclarecer que o ferro analisado das pilhas (Tabela 2) se refere ao elemento presente em seus componentes internos, excluindo o invólucro externo (feito de aço). ${ }^{37}$ Por isso, o percentual ultrapassa $100 \%$ na pilha alcalina na água do mar.

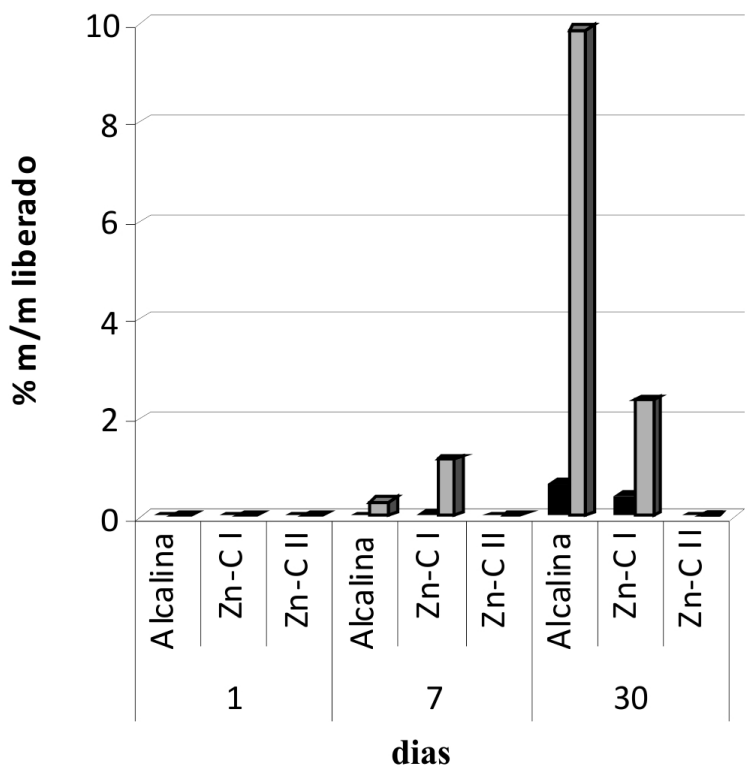

Água chuva $\square$ Chorume

Figura 3. Percentual $(\mathrm{m} / \mathrm{m})$ de Fe liberado das pilhas em relação à quantidade total presente nas mesmas nos ensaios com água da chuva e do chorume

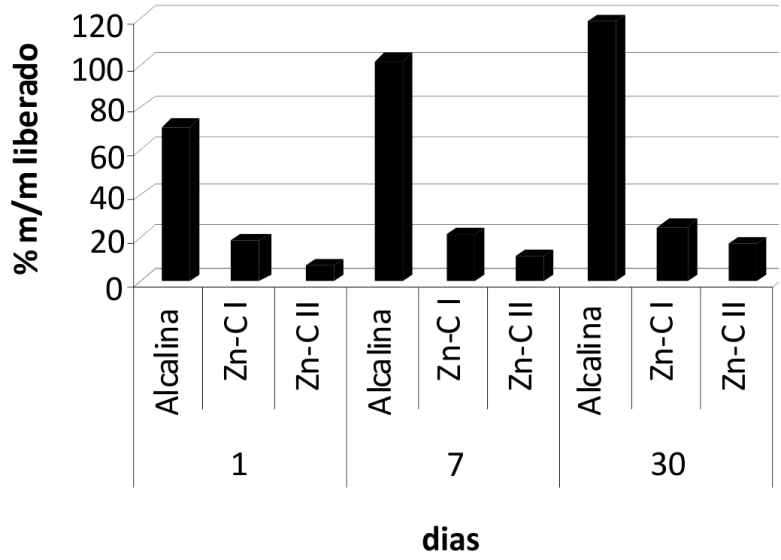

Figura 4. Percentual $(\mathrm{m} / \mathrm{m})$ de Fe liberado das pilhas em relação à quantidade total presente nas mesmas nos ensaios com água do mar 
A quantidade de ferro liberada superou em muito a de manganês e zinco. Desse modo, esse elemento é um bom indicador do início do processo corrosivo das pilhas, atestado pelo ataque do meio lixi-

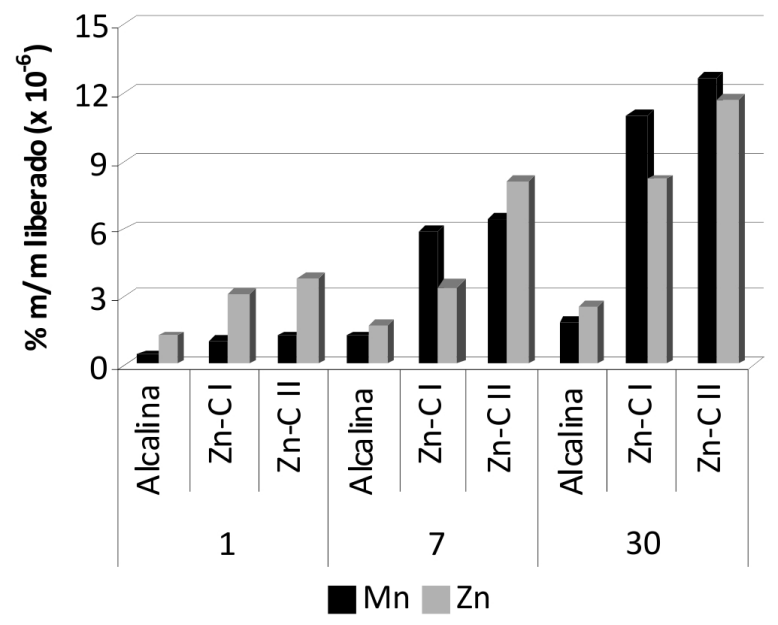

Figura 5. Percentual $(\mathrm{m} / \mathrm{m})$ de Mn e Zn liberados das pilhas em relação à quantidade total presente nas mesmas nos ensaios com água da chuva

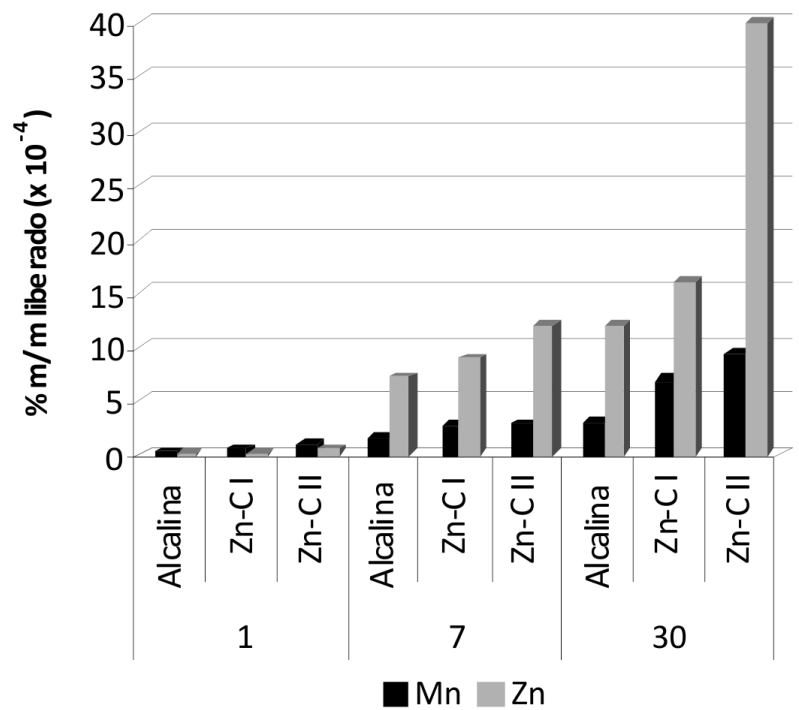

Figura 6. Percentual $(\mathrm{m} / \mathrm{m})$ de Mn e Zn liberados das pilhas em relação à quantidade total presente nas mesmas nos ensaios com água do mar

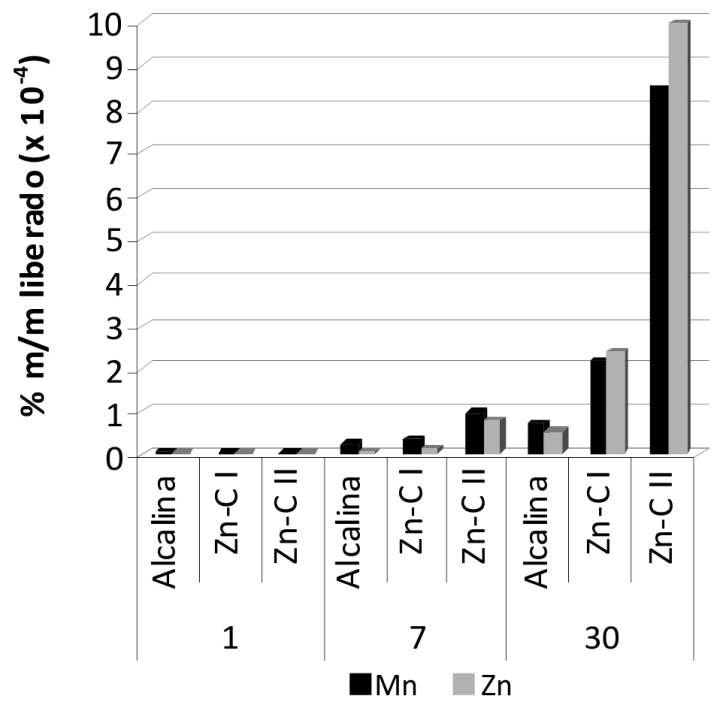

Figura 7. Percentual $(\mathrm{m} / \mathrm{m})$ de Mn e Zn liberados das pilhas em relação à quantidade total presente nas mesmas nos ensaios com chorume

viante ao invólucro externo. A quantidade de ferro liberada obedece à seguinte ordem: pilha alcalina $>\mathrm{Zn}-\mathrm{C}>\mathrm{Zn}-\mathrm{C} \mathrm{II}$, coerente com a espessura do invólucro externo, que cai nessa mesma ordem. O ferro se concentra no precipitado, fato esse justificado pelo $\mathrm{pH}$ de todas as soluções, favorável à precipitação do $\mathrm{Fe}(\mathrm{OH})_{3}$ e pela quantidade do elemento liberada das pilhas. Ele é o elemento largamente dominante no precipitado (mais de $90 \%$ da massa). A redução da quantidade relativa desse metal nos precipitados com o aumento do tempo nos ensaios com a água do mar encontra paralelo com a redução da massa (Tabela 2), face à sua larga dominância nos mesmos, devendo ser atribuída à formação de coloides, conforme discussão anterior.

O comportamento do manganês e do zinco seguiu tendências parecidas, segundo o tipo de pilha e o meio considerado. Para a pilha alcalina, as quantidades relativas no precipitado aumentaram com o tempo de ensaio, especialmente no chorume e na água do mar, cujos pHs finais são alcalinos. O manganês precipita como hidróxido $\left[\mathrm{Mn}(\mathrm{OH})_{2}\right]$, insolúvel em meio alcalino, e oxidável a $\mathrm{MnO}_{2}$ (ou $\mathrm{MnO}(\mathrm{OH})_{2}$ ), também insolúvel, com o tempo. Isso é facilmente notado pelo escurecimento do precipitado, que adquiriu tonalidade marrom própria dos compostos de $\mathrm{Mn}^{\mathrm{iv}}$ (esse processo é interrompido quando o oxigênio dissolvido presente no líquido se esgota). ${ }^{45,53} \mathrm{O}$ zinco precipita como $\mathrm{Zn}(\mathrm{OH})_{2}$, branco, que se dissolve somente em $\mathrm{pH}$ bastante alcalino $(\mathrm{pH}>13)$, vindo a acumular-se no precipitado

Tabela 4. Percentual de Fe, Mn e Zn liberados das pilhas nos precipitados obtidos após ensaios estáticos de lixiviação de pilhas por imersão

\begin{tabular}{|c|c|c|c|c|c|c|c|c|}
\hline Tempo & Pilha & $\begin{array}{c}\mathrm{Fe} \\
\text { água da chuva }\end{array}$ & $\begin{array}{c}\mathrm{Fe} \\
\text { água do mar }\end{array}$ & $\begin{array}{c}\text { Mn } \\
\text { água da chuva }\end{array}$ & $\begin{array}{c}\text { Mn } \\
\text { água do mar }\end{array}$ & $\begin{array}{c}\mathrm{Zn} \\
\text { água da chuva }\end{array}$ & $\begin{array}{c}\mathrm{Zn} \\
\text { água do mar }\end{array}$ & $\begin{array}{c}\mathrm{Zn} \\
\text { chorume* }\end{array}$ \\
\hline & Alcalina & 0 & $92,3 \%$ & 0 & $14,0 \%$ & 0 & $4,4 \%$ & $63,6 \%$ \\
\hline \multirow[t]{3}{*}{$1 \mathrm{dia}$} & $\mathrm{Zn}-\mathrm{C} I$ & 0 & $55,4 \%$ & 0 & $3,3 \%$ & 0 & $9,4 \%$ & $75,7 \%$ \\
\hline & Zn-C II & 0 & $86,2 \%$ & 0 & $19,5 \%$ & 0 & $4,9 \%$ & $81,4 \%$ \\
\hline & Alcalina & $87,1 \%$ & $99,9 \%$ & $63,2 \%$ & $98,9 \%$ & $40,5 \%$ & $99,7 \%$ & $89,7 \%$ \\
\hline \multirow[t]{3}{*}{7 dias } & Zn-C I & $76,0 \%$ & $75,6 \%$ & $72,2 \%$ & $11,6 \%$ & $56,6 \%$ & $28,6 \%$ & $88,8 \%$ \\
\hline & Zn-C II & $92,6 \%$ & $93,1 \%$ & $55,4 \%$ & $26,0 \%$ & $70,5 \%$ & $30,3 \%$ & $93,9 \%$ \\
\hline & Alcalina & $97,5 \%$ & $89,0 \%$ & $71,5 \%$ & $99,7 \%$ & $58,2 \%$ & $99,7 \%$ & $99,5 \%$ \\
\hline \multirow[t]{2}{*}{30 dias } & $\mathrm{Zn}-\mathrm{C}$ I & $98,9 \%$ & $62,5 \%$ & $85,2 \%$ & $41,3 \%$ & $82,9 \%$ & $35,9 \%$ & $93,3 \%$ \\
\hline & Zn-C II & $98,4 \%$ & $74,5 \%$ & $62,6 \%$ & $54,0 \%$ & $85,5 \%$ & $68,5 \%$ & $99,9 \%$ \\
\hline
\end{tabular}

*No chorume, mais de $99 \%$ do ferro se acha no precipitado, independente do tempo de ensaio. No caso do manganês, mais de $99 \%$ também está no precipitado nos ensaios de 7 e 30 dias, enquanto que após 1 dia o percentual insolúvel é 89\% (pilha alcalina) e 93\% (pilhas Zn-C I e II). 
Tabela 5. Concentrações de Na e K $\left(\mathrm{g} \mathrm{L}^{-1}\right)$ nos lixiviados após ensaios estáticos de lixiviação de pilhas por imersão

\begin{tabular}{|c|c|c|c|c|c|}
\hline \multirow[t]{2}{*}{ Pilha } & \multirow[t]{2}{*}{ Tempo de lixiviação } & \multicolumn{2}{|c|}{$\mathrm{Na}$} & \multicolumn{2}{|c|}{$\mathrm{K}$} \\
\hline & & Água da chuva & Água do mar & Água da chuva & Água do mar \\
\hline- & 0 dias* & $<1 \times 10^{-4}$ & $9,8 \pm 0,1$ & $<5 \times 10^{-5}$ & $0,38 \pm 0,03$ \\
\hline Alcalina & & $0,07 \pm 0,01$ & $14,15 \pm 0,35$ & $0,02 \pm 0,01$ & $0,67 \pm 0,03$ \\
\hline $\mathrm{Zn}-\mathrm{C} I$ & $1 \mathrm{dia}$ & $1,04 \pm 0,09$ & $11,35 \pm 0,35$ & $0,01 \pm 0,00$ & $0,31 \pm 0,01$ \\
\hline $\mathrm{Zn}-\mathrm{C}$ II & & $0,60 \pm 0,14$ & $10,47 \pm 0,21$ & $0,01 \pm 0,00$ & $0,38 \pm 0,02$ \\
\hline Alcalina & & $0,77 \pm 0,03$ & $15,70 \pm 0,14$ & $0,20 \pm 0,09$ & $4,60 \pm 0,42$ \\
\hline $\mathrm{Zn}-\mathrm{C}$ I & 7 dias & $2,05 \pm 0,49$ & $12,95 \pm 0,07$ & $0,08 \pm 0,07$ & $0,44 \pm 0,01$ \\
\hline Zn-C II & & $0,66 \pm 0,14$ & $12,13 \pm 0,21$ & $0,08 \pm 0,01$ & $0,41 \pm 0,03$ \\
\hline Alcalina & & $0,90 \pm 0,03$ & $9,00 \pm 0,14$ & $0,80 \pm 0,18$ & $3,20 \pm 0,71$ \\
\hline $\mathrm{Zn}-\mathrm{C} I$ & 30 dias & $3,35 \pm 0,35$ & $8,80 \pm 0,14$ & $0,18 \pm 0,05$ & $0,32 \pm 0,05$ \\
\hline Zn-C II & & $0,80 \pm 0,11$ & $8,93 \pm 0,12$ & $0,13 \pm 0,04$ & $0,36 \pm 0,01$ \\
\hline
\end{tabular}

* 0 dias: lixiviante in natura

junto com o manganês. No caso do chorume, a presença de substâncias húmicas com alta capacidade de complexar e adsorver metais pesados propicia um meio para adsorção dos mesmos..$^{22,54-57}$ Outra justificativa é a interação deles com material particulado presente no chorume, uma vez que, de acordo com a literatura, ${ }^{25,45,46}$ metais pesados podem apresentar elevadas afinidades por essas espécies.

No caso das pilhas $\mathrm{Zn}-\mathrm{C}$, nos ensaios com água do mar e água da chuva, cujo $\mathrm{pH}$ do lixiviado se desloca para valores levemente ácidos (Tabela 1), o percentual insolúvel aumentou regularmente, diferindo-se nesse aspecto em relação ao ferro (Tabela 4). Ainda assim, uma parte considerável desses elementos se manteve solúvel, particularmente na água do mar, face ao $\mathrm{pH}$ dos lixiviados. Quando do emprego do chorume (cujo $\mathrm{pH}$ é alcalino), Mn e $\mathrm{Zn}$ se concentraram fortemente no precipitado. ${ }^{39,45,50}$ Os percentuais em massa de $\mathrm{Mn}$ e $\mathrm{Zn}$ liberados em todos os meios após 30 dias obedecem à ordem: Zn-C II > Zn-C I > alcalina, exatamente a tendência oposta para o ferro, e isso reflete a diferente espessura das blindagens em cada produto considerado: quanto mais delgada, maior a facilidade do meio lixiviante chegar aos componentes internos.

A quantidade total de $\mathrm{Fe}$, $\mathrm{Zn}$ e de Mn liberada nos ensaios obedece à ordem água do mar $>>$ chorume $>>$ água da chuva. Esses três elementos permitem classificar os meios testados em ordem crescente de agressividade: água da chuva < chorume < água do mar. Com base nos dados das Figuras 3 a 7 e nas quantidades totais presentes nas pilhas analisadas (Tabela 3), ${ }^{37}$ após 30 dias sob água do mar, a massa de Fe liberada variou de 35 a $290 \mathrm{mg}$, enquanto que para Mn e Zn a faixa verificada foi de 0,1 a $4 \mathrm{mg}$. Assim, os ensaios com água do mar até 30 dias, embora tenham efeito sobre o invólucro externo, tiveram pouco efeito sobre o catodo e o anodo.

Para as pilhas $\mathrm{Zn}-\mathrm{C}$, após 30 dias nos experimentos cujo pH final do lixiviado é levemente ácido, as concentrações de Fe (água da chuva e do mar) e Mn e Zn (água do mar) ultrapassaram os limites estabelecidos no Anexo G da norma NBR $10004^{28}\left(\mathrm{Fe}-300 \mu \mathrm{g} \mathrm{L}^{-1}\right.$; $\left.\mathrm{Mn}-100 \mu \mathrm{g} \mathrm{L}^{-1} ; \mathrm{Zn}-5000 \mu \mathrm{g} \mathrm{L}^{-1}\right)$ para ensaios de solubilização segundo a norma NBR 10005 (é de se notar que os ensaios com pilhas alcalinas e com chorume não se enquadram nessa situação). ${ }^{28}$ Esse resultado indica que as pilhas podem causar impacto ambiental se descartadas de forma inadequada após um tempo suficientemente longo em condições favoráveis à corrosão.

Na e $K$

A dosagem desses metais alcalinos se constitui num indicativo da profundidade da corrosão da pilha, visto que esses elementos fazem parte da pasta eletrolítica, localizada na parte mais interna/central da pilha. A Tabela 5 apresenta os valores médios das concentrações de $\mathrm{Na}$ e K presentes nos lixiviados.

Dada a baixa agressividade da água da chuva, somente se verificou um aumento perceptível da concentração de potássio no ensaio com a pilha alcalina após 30 dias. Mesmo assim, os metais alcalinos liberados pelas pilhas estão em concentração muito superior àquela dos demais metais e são os responsáveis por elevar a condutividade da água da chuva (Tabela 1).

Tendo em vista a maior agressividade da água do mar, o aumento da concentração do potássio é notável. O sódio também apresenta aumentos expressivos das quantidades liberadas pelas pilhas nesse meio. Apesar das quantidades maiores de $\mathrm{Na}$ e $\mathrm{K}$ liberadas nos ensaios com água do mar, a condutividade (Tabela 1) sofreu redução em relação à amostra original. Esse fato e a queda das concentrações após 30 dias devem estar ligadas a fenômenos de adsorção pelos precipitados formados durante os experimentos.

No caso do chorume, os metais alcalinos estão em concentração abaixo do limite de detecção; fenômenos de retenção (tais como adsorção em sólidos) explicam esse fato..$^{22,53-56}$ A pouca variação da condutividade do chorume nos ensaios com todas as pilhas nesse meio (Tabela 1) pode ser explicada com base nesse resultado.

\section{CONCLUSÕES}

A ordem de hierarquia dos lixiviantes quanto à sua agressividade frente às pilhas é: água do mar > chorume > água da chuva, de conformidade com as características físico-químicas desses meios. Os testes estáticos indicaram que, após 30 dias, mesmo na água do mar (o meio mais agressivo), a quantidade de metais pesados liberada do interior das pilhas foi pequena. Dentre as pilhas analisadas a liberação de metais obedeceu à ordem: pilha $\mathrm{Zn}-\mathrm{C}$ II > pilha $\mathrm{Zn} \mathrm{C} \mathrm{I} \mathrm{>}$ pilha alcalina, exceto para o ferro, cuja ordem observada é a inversa. Ambos os resultados estão relacionados às diferentes espessuras dos invólucros externos de aço das pilhas.

Os metais objeto da Resolução 401/2008 do $\operatorname{CONAMA}^{32}(\mathrm{~Pb}, \mathrm{Cd}$ e $\mathrm{Hg}$ ) distribuíram-se preferencialmente no lixiviado, apesar do $\mathrm{pH}$ ser favorável à precipitação dos mesmos. Isso se deve à baixa quantidade desses metais nas pilhas, dificultando que os produtos de solubilidade de seus sais pouco solúveis sejam atingidos. Porém, é preciso lembrar que esses resultados se referem a testes com uma única pilha do tipo AA num volume de lixiviante pré-determinado $(150 \mathrm{~mL})$.

Após 30 dias, os principais elementos constituintes das pilhas (Fe, $\mathrm{Mn}$ e $\mathrm{Zn}$ ) distribuem-se preferencialmente no precipitado, especialmente no caso da pilha alcalina e quando se emprega o chorume. 
$\mathrm{O}$ pH levemente ácido do lixiviado das pilhas $\mathrm{Zn}-\mathrm{C}$ nos ensaios com água do mar e água da chuva aumentou perceptivelmente o percentual desses elementos em solução. O ferro é um bom indicador de corrosão do invólucro externo das pilhas.

Os metais alcalinos $\mathrm{Na}$ e $\mathrm{K}$ se mostraram bons indicadores de corrosão das pilhas: como estão localizados nas pastas eletrolíticas das pilhas, a parte mais central das mesmas, a liberação desses elementos indica a acessibilidade do lixiviante à pilha como um todo. Eles respondem pelo aumento da condutividade da água da chuva; fenômenos de adsorção por precipitados e material insolúvel interferiram nessa tendência nos demais casos. A liberação de metais alcalinos é acompanhada pela de outros íons $\left(\mathrm{H}_{3} \mathrm{O}^{+}\right.$ou $\left.\mathrm{OH}^{-}\right)$, modificando o $\mathrm{pH}$ do lixiviante. Assim, a pasta eletrolítica pode ser considerada como a que afeta diretamente a acidez do lixiviante e, eventualmente, a condutividade.

Muito se tem discutido sobre o real impacto ambiental decorrente do descarte de pilhas e baterias. Embora os teores de mercúrio, cádmio e chumbo tenham sofrido forte redução (ou mesmo eliminação) nos produtos atuais ${ }^{37}$ a preocupação ambiental persiste porque existem ainda quantidades importantes de chumbo nas pilhas $\mathrm{Zn}-\mathrm{C}$ e as pilhas podem alterar propriedades físico-químicas da água (como o $\mathrm{pH}$ ). Mesmo manganês e zinco, embora sejam menos tóxicos (por massa) do que mercúrio, cádmio e chumbo, estão presentes em quantidades muito maiores. A toxicidade não se manifesta apenas pela periculosidade em si, mas também, pela quantidade disponível para interagir com o ambiente. Portanto, pilhas e baterias devem ser consideradas um resíduo que merece um tratamento especial (segregação da fonte), evitando que sejam descartadas em locais como lixões, terrenos baldios, rios e similares. A disposição em aterros sanitários é preconizada pela Resolução 401/2008, ${ }^{32}$ mas apenas cerca de $11 \%$ dos municípios brasileiros dispõem desses aterros; que dizer das regiões onde tudo para diretamente no meio ambiente? O cidadão deve conscientizar-se de que pilhas e baterias devem ser coletadas seletivamente e destinadas preferencialmente à reciclagem, através da participação ativa na logística reversa desses produtos. ${ }^{36}$ Quanto mais cedo se fizer esse trabalho de conscientização, melhores perspectivas teremos no futuro.

\section{MATERIAL SUPLEMENTAR}

O material suplementar, disponível gratuitamente em http:// quimicanova.sbq.org.br na forma de arquivo PDF, com acesso livre, apresenta: análise química de metais nos meios lixiviantes empregados (Tabela 1S); caracterização físico-química do chorume (Tabela $2 \mathrm{~S}$ ); aspecto visual de pilhas alcalinas submetidas à ação da água do mar nos ensaios estáticos (Figura 1S); aspecto visual de pilhas $\mathrm{Zn}-\mathrm{C}$ sob a ação da água da chuva (Figura $2 \mathrm{~S}$ ) e do chorume (Figura 3S).

\section{AGRADECIMENTOS}

À Fundação José Bonifácio (FUJB), à Fundação de Apoio à Computação Científica e ao CNPq pelo auxílio financeiro. À Central de Tratamento de Resíduos de Nova Iguaçu (CTR-NI), que gentilmente cedeu a amostra de chorume para a realização deste trabalho.

\section{REFERÊNCIAS}

1. Formoso, M. L. L.; An. Acad. Bras. Cienc. 2006, 78, 809

2. Rose, A. W.; Hawkes, H. E.; Webb, J. S.; Geochemistry in Mineral Exploration, $2^{\text {nd }}$ ed., Academic Press: Londres, 1979, p. 129-148.

3. Pendowski, J. J.; An Assessment of Laboratory Leaching Tests for Predicting the Impacts of Fill Material on Ground Water and Surface Water Quality, Report to the Washington State Department of Ecology: Olympia, Dec. 2003.
4. Cauduro, F.; Dissertação de Mestrado, Universidade Federal de Santa Catarina, Brasil, 2003.

5. Cappuyns, V.; Swennen, R.; J. Hazard. Mater. 2008, 158, 185.

6. van Herreweghe, S.; Swennen, R.; Cappuyns, V.; Vandecasteele, C.; J. Geochem. Explor. 2006, 76, 113.

7. Aquino, A. J. A.; Tunega, D.; Pasalic, H.; Haberhauer, G.; Gerzabek, M. H.; Lischka, H.; Chem. Phys. 2008, 349, 69.

8. Kaschl, A.; Römheld, V.; Chen, Y.; J. Environ. Qual. 2006, 31, 1885.

9. Todorovic, J.; Ecke, H.; Leaching Tests for Assessment of Mobility of Inorganic Contaminants from Solidified Incineration Residues - Literature Review. Report N ${ }^{\circ}$ 2004:01, Division of Waste Science and Technology: Lulea, April 2004.

10. Junior, V. N. C.; Rev. Tecnol. 2004, 25, 61.

11. Souza, P. A.; Mello, W. Z.; Maldonado, J.; Evangelista, H.; Quim. Nova 2006, 29, 471.

12. Migliavacca, D.; Teixeira, E. C.; Wiegand, F.; Machado, A. C. M.; Sanchez, J.; Atmos. Environ. 2006, 39, 1829.

13. Leal, T. F. M.; Fontenele, A. P. G.; Pedrotti, J. J.; Quim. Nova 2004, 27 , 855.

14. Rocha, F. R.; Silva, J. A. F.; Lago, C. L.; Fornaro, A.; Gutz, I. G. R.; Atmos. Environ. 2003, 37, 105.

15. Martins, C. R.; de Andrade, J. B.; Quim. Nova 2002, 25, 259.

16. Mirlean, N.; Vanz, A.; Baisch, P.; Quim. Nova 2000, 23, 590.

17. Bricker, O. P.; Rice, K. C.; Ann. Rev. Earth Planet. Sci. 1993, 21, 151.

18. Hirose, K.; Anal. Sci. 2006, 22, 1055

19. Rahmi, D.; Zhu, Y.; Fujimori, E.; Umemura, T.; Haraguchi, H.; Talanta 2007, 72, 600 .

20. Gentil, V.; Corrosão, $3^{\text {a }}$ ed., LTC: Rio de Janeiro, 1996, p. 155-199.

21. Byrne, R. H.; Geochem. Trans. 2002, 3, 11.

22. Kjeldsen, P.; Barlaz, M. A.; Rooker, A. P.; Baun, A.; Ledin, A.; Christensen, T. H.; Crit. Rev. Environ. Sci. Technol. 2002, 32, 297.

23. Morais, J. L.; Sirtori, C.; Peralta-Zamora, P. G.; Quim. Nova 2006, 29, 20.

24. Celere, M. S.; Oliveira, A. S.; Trevilato, T. M. B.; Segura-Muñoz, S. I.; Cad. Saúde Pública 2007, 23, 939.

25. Christensen, T. H.; Kjeldsen, P.; Bjerg, P. L.; Jensen, D. L.; Christensen, J. B.; Baun, A.; Albrechtsen, H. J.; Heron, G.; Appl. Geochem. 2001, 16, 659.

26. Furtado, J. S.; Baterias Esgotadas: Legislações \& Gestão, Relatório elaborado para o Ministério do Meio Ambiente, São Paulo, Brasil, fevereiro 2004.

27. Almeida, M. F.; Xará, S. M.; Delgado, J.; Costa, C. A.; Waste Manage. 2009, 29, 342

28. Associação Brasileira de Normas Técnicas; NBR 10004, ABNT: Rio de Janeiro, 2004; NBR 10005, ABNT: Rio de Janeiro, 2004; NBR 10006, ABNT: Rio de Janeiro, 2004.

29. Souza, C. C. B. M.; Oliveira, D. C.; Tenório, J. A. S.; J. Power Sources 2001, 103, 120.

30. http://www.ehso.com/cssepa/TCLP_from\%20EHSOcom_Method_1311. pdf, acessada em Dezembro 2010.

31. Directiva 2006/66/CEE do Conselho, de 06/09/2006, Jornal Oficial da União Européia, 26/09/2006.

32. Resolução $N^{\circ} 401$ do Conselho Nacional de Meio Ambiente (CONAMA), de 04/11/2008, Diário Oficial da União, 05/11/2008.

33. Agourakis, D. C.; Camargo, I. M. C., Cotrim, M. B.; Flues, M.; Quim. Nova 2006, 29, 960.

34. Gazano, V. S. O.; Dissertação de Mestrado, Universidade de São Paulo, Brasil, 2006.

35. Panero, S.; Romoli, C.; Achilli, M.; Cardarelli, E.; Scrosati, B.; J. Power Sources 1995, 57, 9 .

36. Lei No 12305 (Política Nacional de Resíduos Sólidos), de 02/08/2010, Diário Oficial da União, 03/08/2010.

37. Silva, B. O.; Câmara, S. C.; Afonso, J. C.; Neumann, R.; Alcover Neto, A.; Quim. Nova 2011, 34, 812. 
38. Karnchanawong, S.; Limpiteeprakan, P.; Waste Manage. 2009, 29, 550.

39. Feigl, F.; Spot Tests in Inorganic Analysis, Elsevier: Amsterdam, 1958.

40. Adriano, D. C.; Trace Elements in Terrestrial Environments: Biogeochemistry, Bioavailability, and Risks of Metals, $2^{\text {nd }}$ ed., Springer-Verlag: New York, 2001, p. 30-59.

41. Tripathy, S. S.; Kanungo, S. B.; J. Colloid Interface Sci. 2005, 284, 30.

42. Kanungo, S. B.; Tripathy, S. S.; Rajeev. A.; J. Colloid Interface Sci. 2004, 269, 1 .

43. Mizoguchi, T.; Ishii, Y.; Okada, T.; Kimura, M.; Kihira, H.; Corros. Sci. 2005, 47, 2477.

44. Chen, Y. Y.; Chung, S. C.; Shih, H. C.; Corros. Sci. 2006, 48, 3547.

45. van der Sloot, H. A.; Meeussen, J. C. L.; van Zomeren, A.; Kosson, D. S.; J. Geochem. Explor. 2006, 88, 72.

46. Russo, M. A. T.; Tese de Doutorado, Universidade do Minho, Portugal, 2005.

47. Øygard, J. K.; Gjengedal, E.; Mobbs, H. J.; J. Hazard. Mater. 2008, 153, 751.
48. Baun, D. L.; Christensen, T. H.; Waste Manage. 2004, 22, 3.

49. Renou, S.; Givaudan, J. G.; Poulain, S.; Dirassouyan, F.; Moulin, P.; J. Hazard. Mater. 2008, 150, 468.

50. Kulikowska, D.; Klimiuk, E.; Bioresour. Technol. 2008, 99, 5981.

51. Almeida, M. F.; Xará, S. M.; Delgado, J.; Costa, C. A.; Waste Manage. 2006, 26, 466.

52. Recknagel, S.; Richter, A.; Richter, S.; Waste Manage. 2009, 29, 1213.

53. Afonso, J. C.; Barandas, A. P. M. G.; Silva, G. A. P.; Fonseca, S. G.; Quim. Nova 2003, 26, 573 .

54. Karlsson, T.; Elgh-Dalgren, K.; Björn, E.; Skyllberg, U.; Geochim. Cosmochim. Acta 2007, 71, 604

55. Dijkstra, J. J.; Meeussen, J. C. L.; van der Sloot, H. A.; Comans, R. N. J.; Appl. Geochem. 2008, 23, 1544.

56. van Zomeren, A.; Comans, R. N. J.; Environ. Sci. Technol. 2004, 38, 3927.

57. Garcia-Mina, J. M.; Org. Geochem. 2006, 37, 1960. 


\section{SIMULAÇÃO DO INTEMPERISMO NATURAL DE PILHAS ZINCO-CARBONO E ALCALINAS}

Sílvio Carrielo Câmara e Júlio Carlos Afonso*

Departamento de Química Analítica, Instituto de Química, Universidade Federal do Rio de Janeiro, Av. Athos da Silveira Ramos, 149, B1. A, 21941-909 Rio de Janeiro - RJ, Brasil

Lilian Irene Dias da Silva, Nelma Nogueira Domingues e Arnaldo Alcover Neto

Centro de Tecnologia Mineral, Av. Pedro Calmon, 900, 21941-908 Rio de Janeiro - RJ, Brasil

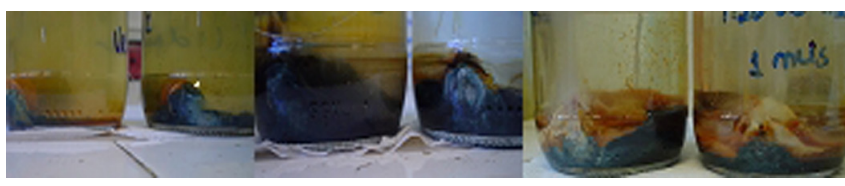

Figura 1S. Aspecto do polo negativo de pilhas alcalinas expostas à ação da água do mar após 1 dia (esquerda), 7 dias (centro) e 30 dias (direita)

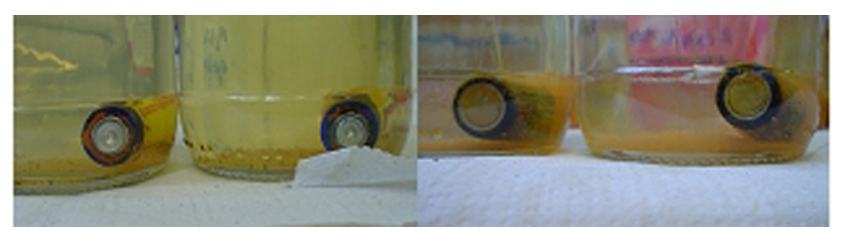

Figura 2S. Aspecto do polo negativo de pilhas Zn-C I expostas à ação da água da chuva após 7 dias (esquerda) e 30 dias (direita)

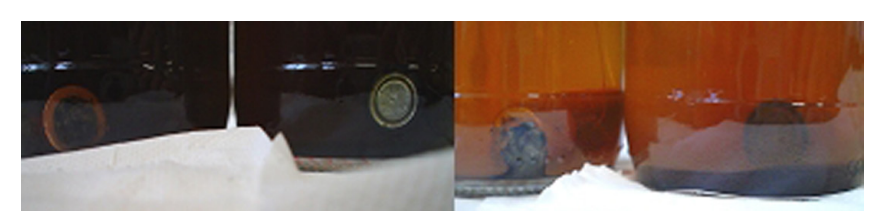

Figura 3S. Aspecto do polo negativo de pilhas Zn-C I expostas à ação do chorume após 7 dias (esquerda) e 30 dias (direita)
Tabela 1S. Análises de metais nos meios de lixiviação

\begin{tabular}{lccc}
\hline Metal & $\begin{array}{c}\text { Concentração } \\
\text { água da chuva }\end{array}$ & $\begin{array}{c}\text { Concentração } \\
\text { água do mar }\end{array}$ & $\begin{array}{c}\text { Concentração } \\
\text { chorume }^{\mathrm{a}}\end{array}$ \\
\hline $\mathrm{Pb}$ & $321,0 \mu \mathrm{g} \mathrm{L}^{-1}$ & $453,0 \mu \mathrm{g} \mathrm{L}^{-1}$ & $48,0 \mu \mathrm{g} \mathrm{L}^{-1}$ \\
$\mathrm{Cd}$ & $26,6 \mu \mathrm{g} \mathrm{L}^{-1}$ & $44,3 \mu \mathrm{g} \mathrm{L}^{-1}$ & $18,0 \mu \mathrm{g} \mathrm{L}^{-1}$ \\
$\mathrm{Hg}$ & $6,9 \mu \mathrm{g} \mathrm{L}^{-1}$ & $6,5 \mu \mathrm{g} \mathrm{L}^{-1}$ & $<0,1 \mu \mathrm{g} \mathrm{L}^{-1}$ \\
$\mathrm{Mn}$ & $8,9 \mu \mathrm{g} \mathrm{L}^{-1}$ & $25,1 \mu \mathrm{g} \mathrm{L}^{-1}$ & $0,3 \mathrm{mg} \mathrm{L}^{-1}$ \\
$\mathrm{Zn}$ & $14,5 \mu \mathrm{g} \mathrm{L}^{-1}$ & $25,0 \mu \mathrm{g} \mathrm{L}^{-1}$ & $0,3 \mathrm{mg} \mathrm{L}^{-1}$ \\
$\mathrm{Fe}$ & $44,1 \mu \mathrm{g} \mathrm{L}^{-1}$ & $101,0 \mu \mathrm{g} \mathrm{L}^{-1}$ & $6,0 \mathrm{mg} \mathrm{L}^{-1}$ \\
$\mathrm{Na}$ & $<0,10 \mathrm{mg} \mathrm{L}^{-1}$ & $9,8 \mathrm{~g} \mathrm{~L}^{-1}$ & $\mathrm{nd}$ \\
$\mathrm{K}$ & $<0,05 \mathrm{mg} \mathrm{L}^{-1}$ & $382 \mathrm{mg} \mathrm{L}^{-1}$ & $\mathrm{nd}$ \\
\hline a - Determinados por ICP-OES, exceto Na e K, determinados por AAS; &
\end{tabular}

Tabela 2S. Análises físico-químicas do chorume

\begin{tabular}{lc}
\hline$* \mathrm{pH}$ & 7,6 \\
$*$ Condutividade $\left(\mathrm{mS} \mathrm{cm}^{-1}\right)$ & 16,67 \\
Sólidos totais $\left(\mathrm{mg} \mathrm{L}^{-1}\right)$ & 9376 \\
Cor $(\mathrm{uH})$ & 8317 \\
Alcalinidade total $\left(\mathrm{mg} \mathrm{L}^{-1} \mathrm{CaCO}_{3}\right)$ & 361,4 \\
$\mathrm{DBO}_{5}\left(\mathrm{mg} \mathrm{L}^{-1} \mathrm{O}_{2}\right)$ & 805 \\
$\mathrm{DQO}\left(\mathrm{mg} \mathrm{L}^{-1} \mathrm{O}_{2}\right)$ & 3216 \\
$\mathrm{DBO}_{5} / \mathrm{DQO}$ & 0,25 \\
$\mathrm{NH}_{3}\left(\mathrm{mg} \mathrm{L}^{-1}\right)$ & $<0,1$ \\
Fósforo total $\left(\mathrm{mg} \mathrm{L}^{-1}\right)$ & 4,48 \\
\hline
\end{tabular}

*pH e condutividade medidos a $25^{\circ} \mathrm{C}$. $\mathrm{O}$ pH $(7,6)$ e o valor da razão $\mathrm{DBO}_{5} /$ $\mathrm{DQO}(0,25)$ do chorume sugerem que essa amostra provém de aterro de idade intermediária (5-10 anos), encontrando-se provavelmente na fase metanogênica inicial. ${ }^{22-24} \mathrm{O}$ aterro donde proveio a amostra começou a operar em 2003. 